\title{
Anti-proliferative Activities of Metallic Nanoparticles in an in Vitro Breast Cancer Model
}

\author{
Samah A Loutfy ${ }^{1 *}$,Nadia AAl-Ansary ${ }^{2}$,Nour T Abdel-Ghani ${ }^{3}$, Ahmed R Hamed $^{4}$, \\ Mona B Mohamed ${ }^{2}$, James D Craik ${ }^{5}$, Taher A.Salah Eldin ${ }^{6}$, Ahmed M Abdellah ${ }^{2}$, \\ Yassmein Hussein ${ }^{7}$, M T M Hasanin ${ }^{7}$, Serag Eldin I Elbehairi ${ }^{8}$
}

\begin{abstract}
Aims: To investigate effect of metallic nanoparticles, silver (AgNPs) and gold nanoparticles (AuNPs) as antitumor treatment in vitro against human breast cancer cells (MCF-7) and their associated mechanisms. This could provide new class of engineered nanoparticles with desired physicochemical properties and may present newer approaches for therapeutic modalities to breast cancer in women. Materials and Methods: A human breast cancer cell line (MCF-7) was used as a model of cells. Metallic nanoparticles were characterized using UV-visible spectra and transmission electron microscopy (TEM). Cytotoxic effects of metallic nanoparticles on MCF-7 cells were followed by colorimetric SRB cell viability assays, microscopy, and cellular uptake. Nature of cell death was further investigated by DNA analysis and flow cytometry. Results: Treatment of MCF-7 with different concentrations of 5-10nm diameter of AgNPs inhibited cell viability in a dose-dependent manner, with IC50 value of 6.28 $\mu \mathrm{M}$, whereas treatment of MCF-7 with different concentrations of 13-15nm diameter of AuNPs inhibited cell viability in a dose-dependent manner, with IC50 value of $14.48 \mu \mathrm{M}$. Treatment of cells with a IC50 concentration of AgNPs generated progressive accumulation of cells in the $S$ phase of the cell cycle and prevented entry into the M phase. The treatment of cells with IC50 concentrations of AuNPs similarly generated progressive accumulation of cells in sub-G1 and $S$ phase, and inhibited the entrance of cells into the $M$ phase of the cell cycle. DNA fragmentation, as demonstrated by electrophoresis, indicated induction of apoptosis. Conclusions: Our engineered silver nanoparticles effectively inhibit the proliferation of human breast carcinoma cell line MCF-7 in vitro at high concentration $(1000 \mu \mathrm{M})$ through apoptotic mechanisms, and may be a beneficial agent against human carcinoma but further detailed study is still needed.
\end{abstract}

Keywords: Metallic nanoparticles - anti-proliferative activity - breast cancer cell line - Cytotoxicity

Asian Pac J Cancer Prev, 16 (14), 6039-6046

\section{Introduction}

Metallic nanoparticles (silver and gold) have been reported to elicit potent toxic effects and anti-proliferative activity against various tumors (Daduang et al., 2015). The proposed mechanism of cytotoxic effects of silver and gold nanoparticles (AgNPs, AuNPs) was through their capacity to disrupt mitochondrial respiratory chain and to produce reactive oxygen species (ROS), this cause interruption of ATP synthesis and in turn initiate expression of apoptotic genes, DNA damage and cell death (Buzea et al., 2007; Selim and Hendi, 2012).

Nanoscale materials have emerged as a novel plateform in cancer nanotechnology due to their high surface area to volume ratio and their unique physico-chemical properties
(Kang et al., 2012). Metallic nanoparticles such as silver and gold are known as plasmonic materials; they have a marked ability to absorb and scatter light at a frequency that is resonant with their surface plasmon oscillation. This resonance frequency depends on particle shape, size, and the density of the particle's electron distribution and the surrounding dielectric environment. It thus provides very useful information regarding particle properties. Production and characterization of silver and gold nanoparticles have not only raised the potential for wider therapeutic application of silver and gold but it have also made them suitable for specific biomedical applications such as targeting therapy (Loutfy et al., 2013). Recent reports have demonstrated that the use of metallic nanoparticles, provides an opportunity for novel antitumor

${ }^{1}$ Virology and Immunology Unit, Cancer Biology Department, National Cancer Institute, ${ }^{2}$ Photochemistry \& Photobiology, LAMPA, National Institute of Laser Enhanced Sciences, ${ }^{3}$ Chemistry Department, Faculty of Science, Cairo University, ${ }^{4}$ Phytochemistry Department and Center of Excellence for Advanced Sciences, National Research Centre, ${ }^{6}$ Director of Nanotechnology Characterization Center, Agricultural Research Center, ${ }^{7}$ Nanotech,6th October, Dreamland, ${ }^{8}$ Egyptian Organization for Biological Products and Vaccines, Agouza, Giza, Egypt, ${ }^{5}$ Biochemistry Department, Faculty of Medicine, Health Sciences Center, Kuwait University, Kuwait *For correspondence: samaly183@yahoo.com 
therapies with reduced risk for development of resistance where several studies have proven nanoparticle antitumor activity against breast, liver, gastric, colon, lung, cancers (Su et al., 2014).

In Egypt, breast cancer is the most common malignancy in women, accounting for $37.7 \%$ of all female cancers, and is responsible for $29.1 \%$ of female cancer deaths 5 . However, despite a wide spread use, there is a lack of information about cytotoxic effects of metallic nanoparticles to humans at the cellular level and molecular level (Kawata et al., 2009; Satapathy et al., 2013).

However, gold nanoparticles have advantages over other metal nanoparticles due to their biocompatibility and non-cytotoxicity (Priya and Lyer, 2015), its antitumor activity through its selective interaction with heparinbinding glycoproteins, this results in inhibition of endothelial/fibroblast cell proliferation and angiogenesis (Selim and Hendi, 2012). Furthermore, it has been demonstrated that the cytotoxic and genotoxic effect of gold nanoparticles is attributed to their physicochemical properties, cell type and time of exposure.

Regarding silver nanoparticles, they were shown to be highly toxic to different cultured cells, increased lactate dehydrogenas (LDH) leakage and inhibited mitochondrial function in rat liver cells (Hussain et al. 2005), mouse germline stem cells (Braydich-Stole et al., 2005), human fibroblast (Wen et al., 2007), and rat adrenal cell (Hussain et al., 2006). Moreover most of the studies evaluated the acute toxic effects of AgNPs at relatively high dose. Since physicochemical properties of metallic nanoparticles was shown to affect both cellular uptake and the antiproliferative activities against different cell types, we thought it is quiet relevant to investigate antiproliferative and antitumor activities of our engineered metallic nanoparticles using cultures of MCF-7 human breast adenocarcinoma cells as an in vitro model of breast cancer and to compare the results with human normal fibroblasts cells (WISH cells). This may be helpful in exploring newer approaches rather than traditional treatment of cancer disease.

\section{Materials and Methods}

\section{Preparation and characterization of AgNPs}

Spherical silver nanoparticles (AgNPs) were synthesized in an aqueous medium by the chemical reduction of AgNO3 (Handley, 1989) with minor modification. The reduction used $\mathrm{NaBH} 4$ as the reducing agent while sodium citrate and polyvinyl pyrrolidone (PVP) served as a capping material to prevent aggregation and excessive growth of the nascent particles. A mixture of $3 \times 10^{-4} \mathrm{mM}$ of tri-sodium citrate and $0.2 \mathrm{~g}$ PVP was dissolved in $10 \mathrm{ml}$ distilled water and mixed well, with stirring. A $100 \mathrm{~mL}$ volume of $10^{-3} \mathrm{M}$ AgNO3 solution was added to the stirred solution. Half $\mathrm{mL}$ of aqueous solution of $1 \times 10^{-3} \mathrm{M} \mathrm{NaBH} 4$ was then added drop wise. The color of the solution changed from colorless to yellow. UV-VIS absorption spectra were recorded (Perkin-Elmer Lambda 40 spectrophotometer) using $1 \mathrm{~cm}$ matched quartz cells.
Spherical gold nanoparticles (AuNPs) were chemically prepared chemically by the citrate reduction of $\mathrm{HAuCl} 4.3 \mathrm{H} 2 \mathrm{O}$ where sodium citrate served as a capping material to prevent aggregation and further growth of the particles (Handley, 1989). Tri-sodium citrate (0.0388 M, $10 \mathrm{~mL}$ ) was added quickly to a boiling HAuCl4 solution $\left(1 \times 10^{-3} \mathrm{M}, 100 \mathrm{~mL}\right)$. The color of the solution changed from yellow to colorless and finally to wine red which was considered as an indication of the formation of AuNPs. The solution is then refluxed for an additional $15 \mathrm{~min}$, then the heater is turned off and the solution is stirred until it reached room temperature to control the particle size and thus achieving a narrow particle size distribution. The absorption spectrum of the obtained sample was measured via UV-VIS spectrophotometer, and the particle shape and size were characterized using TEM.

\section{Nanoparticle parameters}

Particle size, shape and size distribution profile were determined using the transmission electron microscopy (HRTEM) (Nanotech Company for Photo-Electronic, Dreamland, 6-October, Egypt). A drop from a very dilute sample solution was deposited on an amorphous carbon-coated copper grid and left to evaporate at room temperature. Imaging was accomplished using a Joel JEM-2100 microscope (accelerating voltage $200 \mathrm{kV}$; GatanErlangshen ES500 digital camera).

\section{Particle zeta potential}

Nano ZS apparatus (Malvern Instruments, U.K) was used to determine Zeta Potential of Gold nanoparticles (GNPs) (Handley, 1989). The zeta-potential was determined by electrophoretic light scattering studies performed in an aqueous solution and the Smoluchowski software approximation was used to calculate the zeta potentials. The measurements recorded at $25^{\circ} \mathrm{C}$ and started after $2 \mathrm{~min}$ to allow the temperature to equilibrate.

\section{Cell culture}

MCF-7 breast adenocarcinoma cell line (ATCC, USA) was cultured in RPMI 1640 media(Biowest) supplemented with $10 \%$ fetal bovine serum (Biowest), and antibiotics (2\% penicillin-streptomycin (100 IU/ml), and $0.5 \%$ fungizone (Biowest). The cells were maintained in monolayer culture at $37^{\circ} \mathrm{C}$ under a humidified atmosphere of $5 \% \mathrm{CO}_{2}$. The cells were sub-cultured by trypsinization (0.025\% trypsin and $0.0025 \%$ EDTA; Biowest), and maintained in tissue culture laboratory at the National Institute of Laser Enhanced Sciences (NILES), Giza, Egypt with cryogenic banking of low-passage cells to maintain uniformity of cell properties through the study (Schmidt and Emmons, 1989). Cell numbers and viability were monitored by standard Trypan blue dye exclusion procedures. Growth curves for MCF-7 were determined under baseline conditions prior to investigation of cytotoxicity.

Cell culture and treatment with metallic nanoparticles (AgNPs \& AuNPs)

All materials were sterilized under UV irradiation for 3 hours before their application in cell culture. Serial 
dilutions were prepared in RPMI 1640 (2\% FBS) giving AgNPs and AuNPs concentrations 100, 50, 25, 12 and 6 $\mu \mathrm{M}$. Cytotoxicity was investigated through measurement of cell viability using Sulforhodamine B assay (Skehan et al., 1990). Positive and negative cytotoxicity controls were run in each plate. Negative controls (cells with media only; untreated cells), were set as $100 \%$ viability. Cells subjected to osmotic shock (treated with sterile distilled water) were taken as positive controls (zero viability) were used to subtract background from all OD values. Morphological changes of cells were followed by phase contrast microscopy (40 x magnifications).

\section{Cell viability}

Sulforhodamine B (SRB) assay: The cytotoxicity of the nanomaterials was tested against MCF-7 cells by SRB assay. Exponentially growing cells were collected using $0.25 \%$ Trypsin-EDTA and plated in 96-well plates at 1000-2000 cells/well. Cells were exposed to drug for $72 \mathrm{~h}$ and subsequently fixed with TCA (10\%) for 1 $\mathrm{h}$ at $4{ }^{\circ} \mathrm{C}$. After several washings with PBS, cells were exposed to $0.4 \% \mathrm{SRB}$ solution for $10 \mathrm{~min}$ in dark place and subsequently washed with $1 \%$ glacial acetic acid. After drying overnight, Tris- $\mathrm{HCl}$ was used to dissolve the SRB-stained cells and color intensity was measured at $540 \mathrm{~nm}$ with a micro plate reader ( Biotek Model: ELX 800,USA) (Skehan et al 1990)..

Determination of IC50 for metallic nanoparticles (AgNPs\&AuNPs) in both MCF-7 and normal cell lines

The half maximal inhibitory concentration (IC50) was calculated by the trend line equation (Hansen et al 1989).

\section{Flow Cytometric Cell Cycle analysis}

MCF-7 cells $\left(5 \times 10^{5}\right.$ cells/well) were plated in 6-well microplates. After treatment with $\mathrm{IC}_{50}$ concentration of metallic nanoparticles (AgNPs\&AuNPs), cells were washed twice with PBS, suspended in $300 \mu$ of PBS, and finally fixed with $4 \mathrm{ml}$ of ice-cold $70 \%$ ethanol. To stain with propidium iodide (PI), cells were sedimented by centrifugation, the ethanol was removed and cells washed once with PBS. The cell pellets were then resuspended in $1 \mathrm{ml}$ of PI/Triton X-100 staining solution $(0.1 \%$ Triton $\mathrm{X}-100$ in PBS, $0.2 \mathrm{mg} / \mathrm{ml}$ RNase $\mathrm{A}$, and $10 \mathrm{mg} / \mathrm{ml} \mathrm{PI}$ ) and incubated for 30 minutes at room temperature. The stained cells were analyzed using a MoFlo flow cytometer (DakoCytomation, Glostrup) to calculate the percentages of cells occupying the different phases ofthe cell cycle (Nunez, 2001).

\section{Imaging cellular uptake of metallic nanoparticles (AgNPs \& AuNPs)}

Cells were treated with $100 \mu \mathrm{M}$ of AgNPs or AuNPs for $24 \mathrm{~h}$. Cells were washed with PBS buffer then fixed with $2 \%$ glutaraldehyde for 2 hours and washed twice with PBS before fixation in $1 \%$ OsO4 for 1 hour. Following agarose (1.5\%) enrobing, Spurr's resin embedding, and ultrathin $(50 \mathrm{~nm})$ sectioning, the samples were stained with $2 \%$ aqueous uranyl acetate and $25 \mathrm{mg} / \mathrm{mL}$ lead citrate and imaged with a JEOL 100 S microscope (Zhu et al., 2008).

\section{DNA fragmentation}

Fragmentation of cellular DNA was investigated following treatment of MCF-7 cells with AgNPs at low and high concentrations $\left(10 \mu \mathrm{M}\right.$ and $100 \mu \mathrm{M}, \mathrm{IC}_{50}$ respectively) compared to estimated IC50. But DNA fragmentation was investigated following treatment of MCF-7 cells with AuNPs at low and high concentrations (10 $\mu \mathrm{M}$ and $100 \mu \mathrm{M}, \mathrm{IC}_{50}$ respectively) compared to estimated $\mathrm{IC}_{50}$. A fixed amount (100 ng) of cellular DNA (Genomic DNA Purification Kit, Amersham Biosciences) extracted from treated and untreated cells was subjected to $1.5 \%$ agarose gel electrophoresis in Tris-acetate buffer $\mathrm{pH} 8.2$, stained with $0.5 \mu \mathrm{g} / \mathrm{ml}$ ethidium bromide. The bands were examined under UV transillumination and photographed. Smearing, or presence of many low molecular weight DNA fragments, is a characteristic feature of apoptotic cells (Gopinath et., 2010).

\section{Results}

Characterization of metallic nanoparticles (AgNPs\&AuNPs)

Silver nanoparticles (AgNPs): Following reflux, the silver nitrate solution appeared yellow; inspection of the uv-visible spectrum revealed a peak at $405 \mathrm{~nm}$ characteristic of small-diameter AgNPs23; Figure 1A. A representative TEM image of the AgNPs, (Figure 1B) demonstrates presence of approximately spherical particles, although a few prismatic fragments were also present. The zeta size of AgNPs used in this study was $22 \mathrm{~nm}$ as shown in Figure 1C. The zeta potential of AgNPs

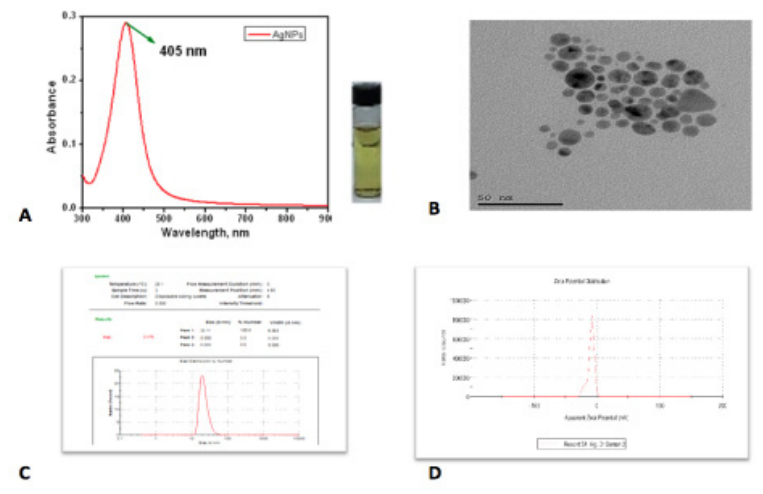

Figure 1. Characterization of Silver Nanoparticles. A) The UV-Vis spectrum, B) TEM, C) Zeta size, D) Zeta potential
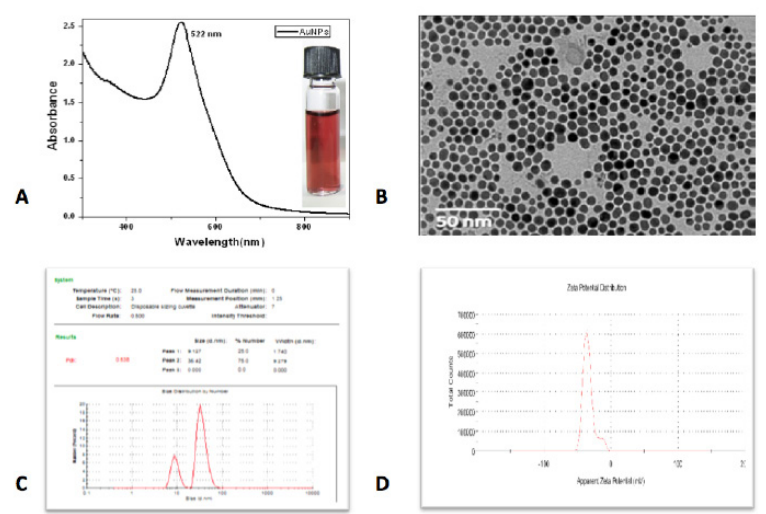

Figure 2. Characterization of Gold Nanoparticles. A) The UV-Vis spectrum , B) TEM, C) Zeta size, D) Zeta Potential 
was found to be $-9.45 \mathrm{mV}$ as illustrated in Figure 1D.

Gold nanoparticles (AuNPs): The visible absorption spectra of the wine red colloidal AuNPs showed a welldefined absorption band at $\lambda \max =522 \mathrm{~nm}$ (Figure 2A), Figure 2B demonstrates TEM image of spherical AuNPs. The zeta size of AuNPs used in this study is $36 \mathrm{~nm}$ as shown in Figure 2C.

Zeta potential of AuNPs was found to be $-33.6 \mathrm{mV}$, this could be due to negative charges of the citrate capping agent (Figure 2D).

Interaction of metallic nanoparticles (AgNPs \& AuNPs) with MCF-7 cells

Light microscopy: MCF-7 cells treated with 100 $\mu \mathrm{M}$ AgNPs for $24 \mathrm{~h}$ (Figure 3A C) show profound morphological changes characteristic of cytotoxicity; shrinkage, granulation and irregular shape, while treatment with $10 \mu \mathrm{M}$ AgNPs (Figure 3A B) demonstrated no significant differences compared to control cells.

MCF-7 cells treated with $100 \mu \mathrm{M}$ AuNPs for $24 \mathrm{~h}$ (Figure 3B C) show profound morphological changes characteristic of cytotoxicity; aggregation of cells and irregular shape, while treatment with $10 \mu \mathrm{M}$ AuNPs demonstrated no significant differences compared to control cells (Figure 3B B).

Transmission electron microscopy: Transmission electron microscopy (TEM) images demonstrated binding and internalization of silver nanoparticles in MCF-7 cells. Aggregation of AgNPs to form nanoparticle clusters on the cell membrane is evident (Figure 4B) compared to untreated cells (Figure 4A). Examination of images at higher magnification shows intracellular nanoparticle clusters, mainly associated with membranes, with most of the dispersed nanoparticles in the cytoplasm. Treatment with AgNPs is associated with disruption and fragmentation of intracellular organelles; localization of AgNPs into the nucleus and nuclear membrane is also apparent.

Figure 4C demonstrated internalization of gold nanoparticles in MCF-7 cells. It was observed to be internalized into cytoplasm, nucleus and into mitochondria.

Cytotoxic effect of metallic nanoparticles (AgNPs \& AuNPs) in MCF-7 cells

The cytotoxic effect of various concentrations of silver nanoparticles was assessed in MCF-7 cell cultures using SRB assay. Our results showed that our engineered metallic nanoparticles (AgNPs\&AuNPs) were safe up to a final concentration of $50 \mu \mathrm{M}$. Our previous study demonstrated that cells treated with concentrated solution of AgNPs 7-9nm size and at $100 \mu \mathrm{M}$ concentration, capped with lactose was safer on cells (viability $79.8 \%$ ) than that treated with AgNPs capped with citrate (viability 34.9\%), such results was estimated based upon MTT colorimetric assay5. In the present study, the cytoxicity of AgNPs of $22 \mathrm{~nm}$ size, capped with lactose was assessed at a $48 \mathrm{~h}$ time point for different concentrations $(100,50,25,12$ and $6 \mu \mathrm{M})$; from the concentration dependence $100 \mu \mathrm{M}$ didn't show any cytotoxic effect on MCF-7 cells based upon SRB assay (Table 1, Figure 5A).

While, the cytotoxic effect of different concentrations

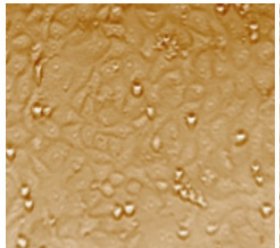

b

C

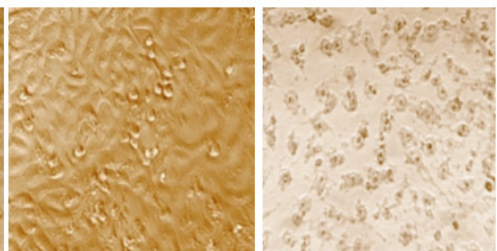

Figure 3A. A) Under Inverted Microscope (40x) Showed Untreated MCF-7 Cell Line as a Control; B) Treatment of MCF-7 with $100 \mathrm{uM}$ AgNPs after $24 \mathrm{~h}$ of Cell Exposure ; C) Treatment of MCF-7 with 1000 uM AgNPs after 24h of Cell Exposure
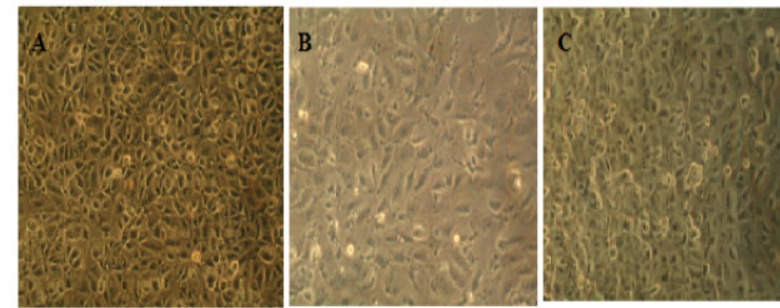

Figure 3B. A) Under Inverted Microscope (40x) Showed Untreated MCF-7 Cell Line as a Control; B) Treatment of MCF-7 with $10 \mu \mathrm{M}$ AuNPs after 24hrs of Cell Exposure; C) Treatment of MCF-7 with $100 \mu \mathrm{M}$ AuNPs after $24 \mathrm{~h}$ of Cell Exposure

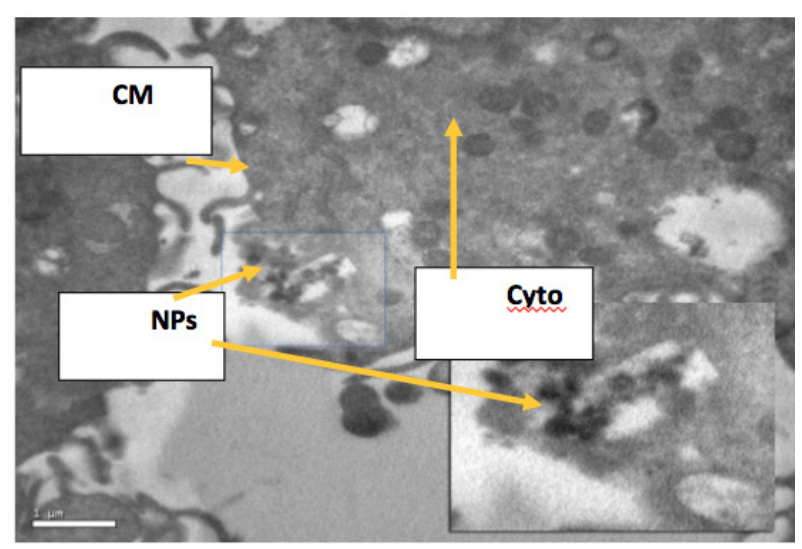

Figure 4B. Localization of AgNPs in MCF-7 Cells by Transmission Electron Microscope Indicated : NPs (nanoparticles), CM (cell membrane), Cyto (cytoplasm)

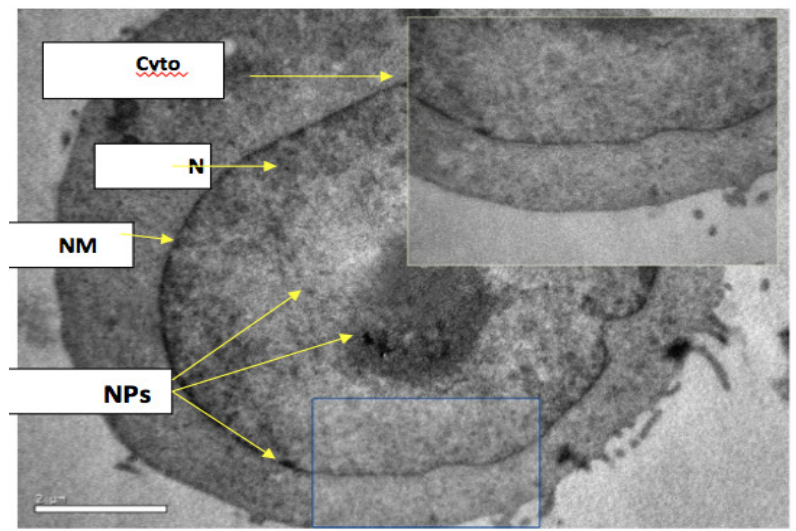

Figure 4C. Localization of AgNPs in MCF-7 Cells by Transmission Electron Microscope Indicated : NPs (nanoparticles), CM (Cell membrane), Cyto (Cytoplasm) 
of gold nanoparticles $(100,50,25,12$ and $6 \mu \mathrm{M})$; from the concentration dependence AuNPs at $100 \mu \mathrm{M}$ showed $15 \%$ toxic effect on MCF-7 cells (Table 2, Figure 5B).

Effect of metallic nanoparticles (AgNPs \& AuNPs) on the cell cycle

The nature of AgNP action was further investigated by flowcytometric analysis of cell cycle and DNA contents of cells treated with $10 \mu \mathrm{M}$ or $1 \mathrm{mg} / \mathrm{L} \mathrm{AgNPs}$ for $24 \mathrm{~h}$. Untreated cells showed the expected cell cycle pattern for continuously growing cells, whereas treated cells showed a progressive accumulation in the $S$ phase of the cell cycle correlating with decreased number of cells in the G2/M phase and G2/G1phase; the distribution of cells in different phases of the cycle is illustrated in Figure 6A. Also, flowcytometric analysis of cell cycle and DNA contents of cells treated with $10 \mu \mathrm{M}$ or $5 \mathrm{mg} / \mathrm{L}$ AuNPs for $24 \mathrm{~h}$ was investigated. Untreated cells showed the expected cell cycle pattern for continuously growing cells, whereas treated cells showed a progressive accumulation in the $\mathrm{S}$ and an increase in the number of cells in sub-G1 phase of cell population indicating presence of apoptotic cells. The distribution of cells in different phases of the cycle is

Table 1. Comparison between the Cytotoxic Effect of AgNPs on MCF-7 Cells and WISH Cells Viability $(\%)$ in the Concentration Rang $(0-100 \mu \mathrm{M})$ after $48 \mathrm{~h}$ of Cells Exposure

\begin{tabular}{llclc}
\hline Conc $(\mu \mathrm{M})$ & \multicolumn{2}{c}{ AgNPs on MCF-7 cells } & \multicolumn{2}{c}{ AgNPs on WISH cells } \\
& O.D & Viability\% & O.D & Viability\% \\
\hline 0 & 1 & 100 & 1 & 100 \\
6.25 & 0.87 & 87 & 0.902 & 90.2 \\
12.5 & 1 & 100 & 0.9 & 90 \\
25 & 0.913 & 91.3 & 0.903 & 93 \\
50 & 0.996 & 99.6 & 0.906 & 90.6 \\
100 & 0.957 & 95.7 & 0.902 & 90.2 \\
\hline
\end{tabular}

Table 2. Comparison between the Cytotoxic Effect of AuNPs on MCF-7 Cells and WISH Cells Viability $(\%)$ in the Concentration Rang $(0-100 \mu \mathrm{M})$ after $48 \mathrm{~h}$ of Cells Exposure

\begin{tabular}{llclc}
\hline Conc $(\mu \mathrm{M})$ & \multicolumn{3}{c}{ AUNPs on MCF-7 cells } & \multicolumn{2}{c}{ AUNPs on WISH cells } \\
& O.D & Viability\% & O.D & Viability\% \\
\hline 0 & 1 & 100 & 1 & 100 \\
6.25 & 1.13 & 113 & 0.95 & 95 \\
12.5 & 1.022 & 102.2 & 0.95 & 95 \\
25 & 1.065 & 106.5 & 0.923 & 92 \\
50 & 1.043 & 104.3 & 0.875 & 87.5 \\
100 & 0.85 & 85 & 0.871 & 87.1 \\
\hline
\end{tabular}
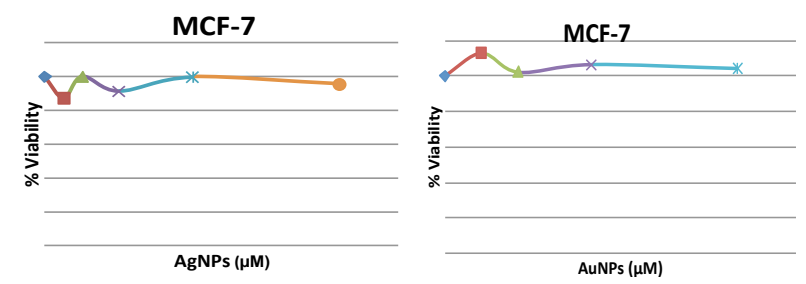

Figure 5. Concentration Dependence of A). AgNPs MCF-7 Cell Cytotoxicity; B). AuNPs MCF-7 Cell Cytotoxicity by SRB Assy
A
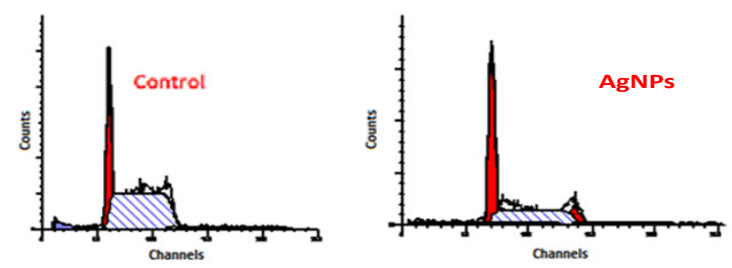

B
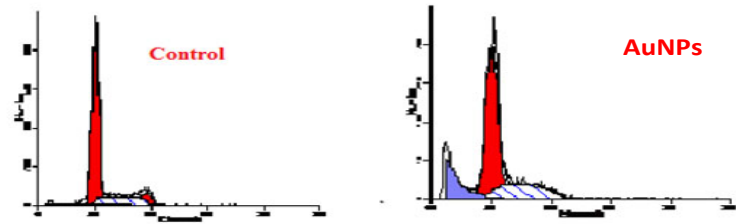

Figure 6. Flow Cytometric Analysis, Shows four Distinct Phases could be Recognized in a Proliferating Cell Population: the G1-, S- (DNA synthesis phase), G2- and M-phase (mitosis). However, G2- and M-phase, which both have an identical DNA content, could not be discriminated based on their differences in DNA content. A). $50 \mu \mathrm{M}$ of AgNPs; B). $50 \mu \mathrm{M}$ of AuNPs

Table 3. Flow Cytometric Analysis of Effect of IC50 conc. of AgNPs and AuNPs

\begin{tabular}{lccc}
\hline & \% G0-G1 & \% S-Phase & \% G2-M \\
\hline Control of AgNPs & 46.37 & 44.26 & 9.37 \\
AgNPs & 27.13 & 72.22 & 0.65 \\
Control of AuNPs & 69.51 & 22.04 & 8.45 \\
AuNPs & 69.7 & 28.15 & 2.14 \\
\hline
\end{tabular}

Table 4. DNA Content of DNA Fragmentation assay after Treatment of Cells with AgNPs

\begin{tabular}{lcc}
\hline Sample & Conc ng/ $\mu 1$ & Ratio (260/280) \\
\hline AgNPs low conc $(10 \mu \mathrm{M})$ & 156 & 1.92 \\
Ag high conc $(100 \mu \mathrm{M})$ & 28 & 1.27 \\
Control (untreated MCF-7) & 763.8 & 2.04 \\
\hline
\end{tabular}

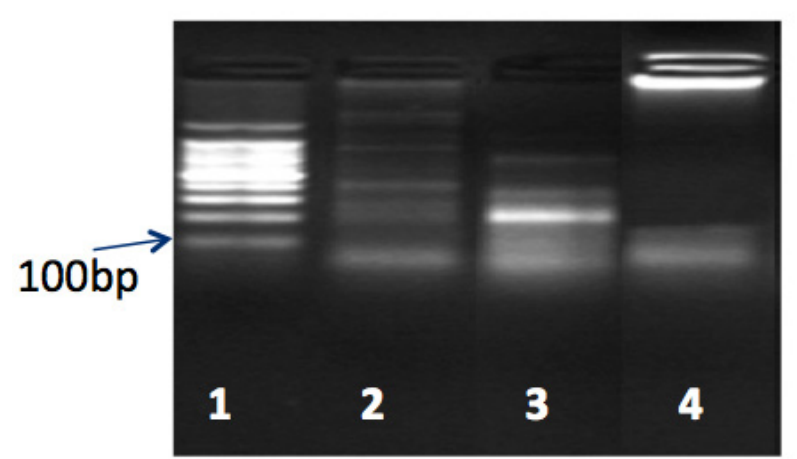

Figure 7A. EB-stained Gel Electrophoresis of DNA Extraction from Untreated and Treated MCF-7 cell Line with Different Concentrations of AgNPs. Lane 2 (treated MCF-7 with $10 \mu \mathrm{M} / \mathrm{ml}$ ), Lane 3 (treated MCF-7 with $100 \mu \mathrm{M} / \mathrm{ml}$ ), lane 4 untreated MCF-7 (cell control), and $100 \mathrm{bp}$ ladder in lane 1

illustrated in Figure 6B. Results are summarized in table 3.

DNA fragmentation of metallic nanoparticles (AgNPs \& AuNPs )

DNA fragmentation analysis was carried out to study the effects of AgNPs on cell stability and replication. 
Table 5. DNA Content of DNA Fragmentation Assay After Treatment of Cells with AuNPs

\begin{tabular}{lcc}
\hline Sample & Conc ng/ $\mu \mathrm{l}$ & Ratio (260/280) \\
\hline Au low conc $(10 \mu \mathrm{M})$ & 119.5 & 1.88 \\
Au high conc $(100 \mu \mathrm{M})$ & 50.8 & 1.27 \\
Control (untreated $\mathrm{MCF}-7)$ & 660.8 & 2.04 \\
\hline
\end{tabular}

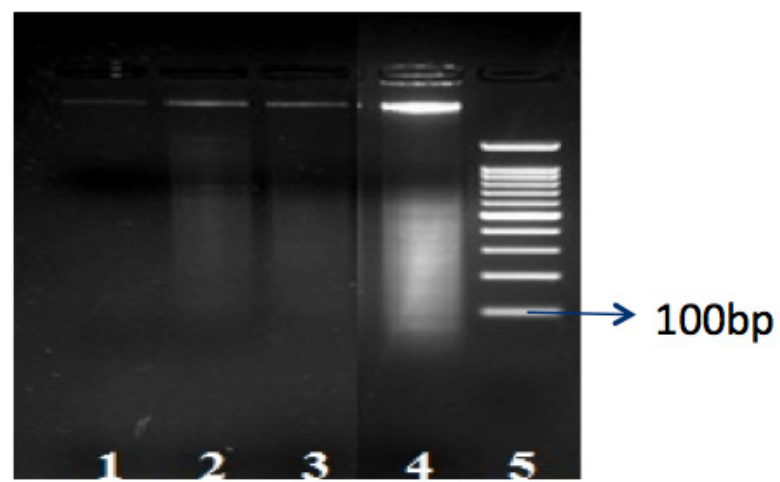

Figure 7B. EB-stained Gel Electrophoresis of DNA Extraction from Untreated and Treated MCF-7 cell Line with Different Concentrations of AuNPs. Lane 1 (treated MCF-7 with $100 \mu \mathrm{M} / \mathrm{ml}$ ), Lane $2 \&$ Lane3 (treated $\mathrm{MCF}-7$ with $10 \mu \mathrm{M} / \mathrm{ml}$ ), lane 4 untreated MCF-7 (cell control), and 100 bp ladder in lane 5

DNA fragmentation characteristic of late apoptosis was observed after treatment of cells with a high concentration of AgNPs $(100 \mu \mathrm{M})$, while much less significant changes were seen when the AgNPs concentration was reduced to $10 \mu \mathrm{M}$. DNA fragmentation was not observed in untreated cells (cell control); in this case DNA was recovered as a clear band (Table 4, Figure 7A). These results point to a potent effect of AgNPs in induction of apoptosis, which may represent a major cytotoxic effect.

Also, effect of AuNPs on cell stability and proliferation was investigation in parallel to the effects of AgNPs. DNA fragmentation characteristic of apoptotic effect was observed after treatment of cells with high concentration of AuNPs $(100 \mu \mathrm{M})$, while much less significant changes were seen when the AuNPs concentration was reduced to $10 \mu \mathrm{M}$ Table (Table 5, Figure 7B).

\section{Discussion}

The use of metal nanoparticles provides an interesting opportunity for development of novel antiviral and anticancer therapies. Integration properties of nanoparticles with biological molecules have lead to the development of diagnostic devices, contrast agents, and important tools in cancel therapy. In the current study MCF-7, an epithelial cell line derived from human breast cancer, provides an in vitro model for breast cancer studies as the cell line has retained several ideal characteristics particular to the mammary epithelium (Wang et al., 2004). To examine anti-tumor activity of our engineered metallic nanoparticles (AgNPs\&AuNPs), MCF-7 cells and normal human fibroblast cell line as control non cancerous cells were treated with AgNPs or AuNPs at concentrations of $10 \mu \mathrm{M}$ and $100 \mu \mathrm{M}$ for $24 \mathrm{~h}$. Qualitative observations of fragmentation of MCF-7 cellular DNA, and microscopic imaging followed cell cycle analysis. In our previous study, cell viability was assessed using standard chromogenic assays. Since there is a possibility that metallic nanoparticles might interfere with redoxbased assays such as the sensitive MTT cell viability assay (Wang et al., 2004; Samberg et al., 2010) beside other limitations (Houghton et al., 2007), therefore we tried to overcome such limitations in the current study by assessing cytotoxicity using the SRB colorimetric assay which is more preferred than MTT assay (Samberg et al., 2010) where it is based upon uptake of the negatively charged pink aminoxanthine dye, sulphorhodamine B (SRB) by basic amino acids in the cells with intact cell membrane. The greater the number of cells, the greater amount of dye is taken up and, after fixing, when the cells are lysed, the released dye will give a more intense colour and greater absorbance (Houghton et al., 2007). However, AgNPs and AuNPs did not show signs of toxicity at the experimental concentration range using SRB assay in the present study. This could be explained by the fact that cell membrane damage represents a late event in the apoptotic process (Wlodkowic et al., 2011).

Regarding impact of physicochemical properties of metallic nanoparticles on antitumor activity, Particle size, concentration of nanoparticles, along with cell type and time of exposure play a crucial role in their antitumor activity and different levels of nanoparticles toxicity. Smaller nanoparticles show a higher accumulation at tumor sites and prolong in vivo half-life due to their avoidable capture by the reticuloendothelial system (Sutradhar and Amin, 2014). Our previous experience showed that the samaller the size of nanoparticles the more toxic effect . Our previous results showed that AgNPs of smaller size $(7-9 \mathrm{~nm})$ at $100 \mu \mathrm{M}(10.78 \mathrm{mg} / \mathrm{L})$ exerted $15 \%$ more toxic effect than that used in the current study $(22 \mathrm{~nm})$ at the same concentration and even in the same cell line. The same observation was detected for AuNPs, the cytotoxic effect of our previous preparation at size of $11-15 \mathrm{~nm}$ exerted $32 \%$ more toxic than that prepared in the current study of $36 \mathrm{~nm}$ size at concentration of $50 \mu \mathrm{M}$ $(15 \mathrm{mg} / \mathrm{L})$ also in the same cell line. When compared our results with that in the literature, Turkish report showed that the lowest mortality rate was obtained for silver nanoparticles at size of $16-20 \mathrm{~nm}$, charges $-38.2 \mathrm{mv}$ at concentration of $10 \mu \mathrm{g} / \mathrm{mL}$, whereas the highest mortality rate was obtained at $120 \mu \mathrm{g} / \mathrm{mL}$ AgNPs with a halfmaximal inhibiting concentration value (IC50) of $40 \mu \mathrm{g} /$ mL (Ciftci et al., 2013).

Regarding gold nanoparticles, previous report showed that gold nanoparticles at size of $21 \mathrm{~nm}$ gave excellent viability at up to $140 \mu \mathrm{g} / \mathrm{ml}$ on MCF-7 (Vijayakumar and Ganesan, 2012).. This may encourge us to do further study with AuNPs size higher than $15 \mathrm{~nm}$ and lower than $36 \mathrm{~nm}$, and continue further molecular analysis for AgNPs of $22 \mathrm{~nm}$ size before its biomedical application.

Moreover, our results showed that the cytotoxic effect of cells treated with AgNPs at $1000 \mu \mathrm{m}$ concentration appeared after $24 \mathrm{~h}$ and was evidenced by alterations in cell morphology which could be due to disturbances in cytoskeletal functions as a result of release of $\mathrm{Ag}+$ ions (Foldbjerg et al., 2011). Cellular clustering was observed 
which may be attributed actions of certain MCF-7 cells as non-professional phagocytes; engulfment of apoptotic cells could cause characteristic microscopic appearance 28 . The demonstration of presence of AgNPs within cells, and the intracellular distribution of AgNPs together with their relationship to intracellular structures and organelles were shown by TEM.

Flow cytometry and electrophoresis of cellular DNA provided insight into the nature of cell death in MCF7 cells exerted by our engineered AgNPs \& AuNPs preparations. It has been proposed that oxidative stress and generation of ROS may be responsible for DNA damage and accumulation of cells in gap 1 (G1), DNA synthesis (S) phase for AgNPs (Foldbjerg et al., 2011; Satapathy et al., 2013) and in sub-G1 and S phase for AuNPs. Both metallic nanoparticles affect entrance of cellular $\mathrm{M}$ phase. It has been proposed that Ag+ might induce P53 and other cell cycle genes thus preventing cells from entering $M$ phase and promoting apoptosis (Asharani et al., 2009), but further molecular analysis is required to confirm such speculation.

Cellular uptake and transport of AuNPs in breast cancer cells (MCF-7) was previously reported (Elmores, 2007). It was found that the particles were first internalized through receptor-mediated endocytosis and trapped into endosomes. Endosomes are then fused with lysosomes for processing before being transported to the cell periphery for excretion. With respect to cytotoxic effect of our AuNPs, may be explained by its ability to create small gaps in cell membranes, allowing a considerable molecular interchange with the surrounding culture medium; produces physiological/inflammatory responses (Chithrani et al 2010; Austin et al., 2011). In contrast to cytotoxic effect of metallic nanoparticles as detected by colorimetric assay, results of cellular DNA fragmentation showed that AgNPs was more toxic than that of AuNPs at concentration of $100 \mathrm{uM}$. However such results are matched with biocompatibility of gold nanoparticles but still further molecular analysis is required before starting in vivo applications.

In conclusion, in the present study, silver nanoparticles $22 \mathrm{~nm}$ in diameter and gold nanopartices $36 \mathrm{~nm}$ in diameter at concentration of $50 \mu \mathrm{M}$ didn't show any cytotoxic effect on human breast cancer cells (MCF-7) or on normal human fibroblast cells (WISH). Higher concentration of AgNPs $(1000 \mu \mathrm{M})$ showed cytotoxic effect on MCf-7 but further analysis is required to investigate mechanism of antitumor activity. In the longer term, it may also open the possibility of new approaches for the scientific investigation of the role of metallic nanoparticles in the heavy clinical burden of breast cancer as a targeting therapy or antimicrobial therapy. Further studies is required to quantitatively investigate changes in apoptotic genes expression profile in response to silver nanoprticles at different time intervals before starting in vivo studies.

We expect that with the introduction of safer nanomaterials together with novel engineering approaches that result in optimally designed nanoparticles, we will be seeing an increasing number of multifunctional nanoparticles enter the clinic in the future.

\section{Acknowledgements}

Our sincere gratitude to the team group of Nanotechnology \& Advanced Materials Central Lab, Agriculture Research Center, Giza, Egypt. Alaa Tamim has been involved as a project man power responsible for establishment and maintenance of cells in lab, and cytotoxicity assay.

Funding provided as Cairo University research project.

\section{References}

Austin LA, Kang B, Yen CW, et al (2011). Plasmonic imaging of human oral cancer cell communities during programmed cell death by nuclear-targeting silver nanoparticles. $J \mathrm{Am}$ Chem Soc, 133, 17594-97.

AshaRani PV, Low Kah Mun G, Hande MP, et al (2009). Cytotoxicity and genotoxicity of silver nanoparticles inhuman cells. ACS Nano, 3, 279-90.

Buzea C, Pacheco I, Robbie K (2007). Nanomaterials and nanoparticles: sources and toxicity. Biointerphases, 2, 17-71.

Braydich-Stolle L, Hussain S, Schlager JJ, et al (2005). In vitro cytotoxicity of nanoparticles in mammalian germline stem cells. Toxicol Sci, 88, 412-9.

Chithrani DB, Dunne M, Stewart J, et al (2010). Cellular uptake and transport of gold nanoparticles incorporated in a liposomal carrier. Nanomedicine: Nanotechnology, Biology and Medicine, 6, 161-9.

ÇIFTÇİ H,TÜRK M, TAMER et al (2013). Silver nanoparticles: cytotoxic, apoptotic and necrotic effects on MCF-7 cells. Turkish Journal of Biology, 37, 573.

Daduang J, Palasap A, Daduang S, et al (2015). Gallic acid enhancement of gold nanoparticle anticancer activity in cervical cancer cells. APJCC, 16, 169-74.

Elmore $S$ (2007). Apoptosis: a review of programmed cell death. Toxicologic pathology, 35, 495-516.

Foldbjerg R, Dang DA, Autrup H (2011). Cytotoxicity and genotoxicity of silver nanoparticles in the human lung cancer cell line, A549. Arch Toxicol, 85, 743-50.

Gopinath P, Gogoi SK, Chattopadhyay A, (2008). Implications of silver nanoparticle induced cell apoptosis for in vitro gene therapy. Nanotechnology, 19, 1-10.

Hussain SM, hess KL, Gearhart JM, et al (2005). In vitro toxicity of nanoparticles in BRL 3A rat liver cells. Toxicol In vitro, 19, 975-83.

Hussain SM, Javorina AK, Schrand AM, (2006). The interaction of manganese nanoparticles with PC-12 cells induces dopamine depletion. Toxicol Sci, 92, 456-63.

Handley DA (1989). Methods for synthesis of colloidal gold. In colloidal gold principles, methods, and applications; Vol 1 (ed. M.A. Hayat) Academic Press, San Diego.

Hansen MB, Nielsen SE, Berg K (1989). Re-examination and further development of a precise and rapid dye method for measuring cell growth/cell kill. J Immunol Methods, 119, 203-10.

Houghton P, Fang R, TechatanawatI,(2007). The sulphorhodamine

(SRB) assay and other approaches to testing plant extracts and derived compounds for Activities related to reputed anticancer activity. Methods, 42, 377-87.

Kang SJ, Ryoo IG, Lee YJ, Kwak MK (2012). Role of the Nrf2heme oxygenase-1 pathway in silver nanoparticle-mediated cytotoxicity. Toxicol Appl Pharmacol, 258, 89-98.

Kawata K, Osawa M, Okabe S (2009). In vitro of silver nanoparticles at noncytotoxic doses to HepG2 human hepatoma cells. Environ Sci Technol, 43, 6046-51. 
Nunez R (2001). DNA measurement and cell cycle analysis by flow cytometry. Curr Issues Mol Biol, 3, 67-70.

Priya KMR and lyer PR (2015). Anticancer studies of the synthesized gold nanoparticles against MCF 7 breast cancer cell lines. Applied nanoscience, 5, 443-8.

Samah A Loutfy, Mona Bakr Mohamed, Nour Tawfik AbdelGhani, et al, (2013). Metallic nanomaterials as drug carriers to decrease side effects of chemotherapy (In vitro: Cytotoxicity Study). J Nanopharmaceutics Drug Delivery, 1, 138-49.

Samberg ME, Oldenburg SJ, Monteiro-Riviere NA (2010). Evaluation of silver nanoparticle toxicity in skin in vivo and keratinocytes in vitro. Environ Health Perspect, 118, 407-13.

Schmidt NJ, Emmons RW (1989). Diagnostic procedures for viral, rickettsial, and chlamydial Infections. American Public Health Association Washington, DC 1989, 957-1065.

Selim ME, Hendi AA (2012). Gold nanoparticles induce apoptosis in MCF-7 human breast cancer cells. Asian Pac J of Cancer Prev, 13, 1617-20.

Skehan P, Storeng R, Scudiero D, et al (1990). New colorimetric cytotoxicity assay for anti-cancer drug screening. $J$ Natl cancer Inst, 82, 1107-12.

Sutradhar KB and Amin L (2014). Nanotechnology in cancer drug delivery and selective Targeting. ISRN Nanotechnology, 939378, 1-12.

Su XY, Liu PD, Wu H, et al, (2014). Enhancement of radiosensitization by metal-based nanoparticles in cancer radiation therapy. Cancer Biol Med, 11, 86-91.

Vijayakumar S and Ganesan S (2012). In vitro cytotoxicity assay on gold nanoparticles with different stabilizing agents. $J$ of nanomaterials, $\mathbf{7 3 4 3 9 8}, 9$.

Wang Y, Jiang JD, Xu D (2004). Mouse mammary tumor viruslike long terminal repeat superantigen in human breast cancer. Cancer Res, 64, 4105-4111.

Wen HC, Lin YN, Jian SR, et al (2007). Observation of growth of human fibroblasts on silver nanoparticles.J Phys, 61, 445-9.

Wlodkowic D, Telford W, Skommer J, et al (2011). Apoptosis and Beyond: Cytometry in studies of programmed cell death. Methods in cell biology, 103, 55-98.

Zhu ZJ, Ghosh PS, Miranda OR (2008). Multiplexed screening of cellular uptake of gold nanoparticles using laser desorption/ ionization mass spectrometry. J Am Chem Soc, 130, 1413943. 